\title{
Influence of site of impact on cognitive impairment persisting long after severe closed head injury
}

\author{
EILEEN SMITH \\ From the Department of Psychological Medicine, \\ National Hospital for Nervous Diseases, Maida Vale, London
}

SYNOPSIS The cognitive abilities of right-handed men who had sustained a severe closed head injury between 10 and 20 years earlier were studied. Results showed that a right-sided impact produced greater deficits than a left-sided impact in both verbal and non-verbal skills. The results are interpreted as reflecting left hemisphere damage due to contrecoup injury. Some evidence that a left frontal impact was apt to result in defective visual-spatial functioning is presented. These observations accord with some theories on the mechanics of head injury and with observations on the predictability of sites of cerebral contusion in brain injury uncomplicated by dural penetration, intracranial infection, or cerebral infarction. The roles of the duration of post-traumatic amnesia, the level of neurological responsiveness at the time of admission to hospital, and the age at which the injury was sustained are also discussed.

This study examines the site of head impact and its relation to cognitive function in a consecutive series of patients who had sustained a severe closed head injury between 10 and 20 years previously. The group comprised patients whose injury had not been complicated by surface compression, intracranial infection, or brain penetration, either traumatic or surgical. In addition they had had a post-traumatic amnesia for at least seven days.

There have been two different approaches to the study of the late sequelae of severe closed head injuries. Using the first, workers have attempted to assess the overall quality of survival as measured by clinical, neurological, and socioeconomic disability together with only a gross sampling of cognitive functions (Miller and Stern, 1965; Lewin, 1965, 1967; Fahy et al., 1967; London, 1967). The second has been principally concerned with showing psychological deficits (Ruesch, 1944; Dencker and Löfving, 1958). However, in all studies the relevance of the site of impact appears to have been neglected, with the single exception of a study of a few patients, mostly alcoholics, with post-traumatic dysphasia (Heilman et al., 1971). Moreover, the results have usually been presented in such a way that it has not been possible to examine the likelihood that one pattern of specific cognitive deficits rather than another may occur after a head injury. This is surprising in view of the observations of Courville (1942), Holbourn (1943), and Lindenberg and Freytag (1960) on the pathology and mechanics of closed head injury and the predictability of sites of cortical contusion.

The present study was undertaken to ascertain whether the degree of impairment of cognitive skills varied with the side of head impact-that is, left or right. Asymmetry of function between the cerebral hemispheres is now well established in dextral man. Studies of patients with focal injuries have shown that the left hemisphere plays the major part in the synthesis of verbal behaviour and that the right hemisphere is concerned with the integration of visuospatial information (Darley, 1967; Milner, 1968).

In addition, the site of the lesion-namely, frontal, lateral, or parietal-duration of posttraumatic amnesia, initial neurological state, age at the time of the accident, and age at which the patients were tested were analysed in relation to impairment of cognitive function. 


\section{METHOD}

PATIENTS A consecutive series of 356 patients who had survived a head injury which had caused a posttraumatic amnesia for a week or more and had been admitted between 1948 and 1961 to the Accident and Neurosurgical Services of the Radcliffe Infirmary, Oxford, were traced and reexamined. This preliminary report concerns cognitive data on the first consecutive 77 dextral men examined whose head injury had not been complicated by surface compression, intracranial infection, or brain penetration and in whom the site of impact could be identified with certainty. In 57 this was deduced from the position and character of the skull fracture, as suggested by Gurdjian and Webster (1958), and in the remaining 20 from the site of the soft-tissue contusion. The site of head impact was classified as right or left and the locus of impact as frontal, lateral, or parietal. Fractures of the temporal bone or running from vertex into temporal bone were designated lateral (as were soft-tissue contusions above the ear); of the frontal, maxillary, or zygomatic bones as frontal; and of parietal or occipital bones as parietal. In cases with frontal or occipital fractures on both sides the site of impact could not be lateralized, and these were excluded from the analysis. The shortest period of post-traumatic amnesia was seven days and the longest periods varied from 29 days to one year.

TABLE 1

DISTRIBUTION OF PATIENTS IN RELATION TO VARIABLES EXAMINED

\begin{tabular}{lrr}
\hline & \multicolumn{2}{c}{ Impact group } \\
\cline { 2 - 3 } & $\begin{array}{c}\text { Left } \\
(n=36)\end{array}$ & $\begin{array}{c}\text { Right } \\
(n=41)\end{array}$ \\
\hline Locus of impact & & \\
$\quad$ Frontal & 21 & 24 \\
$\quad$ Lateral & 6 & 7 \\
$\quad$ Parietal & 9 & 10 \\
Duration of post-traumatic amnesia* & 4 & \\
1 & 15 & 7 \\
2 & 15 & 14 \\
3 & 2 & 4 \\
4 & 3 & \\
Neurological status* & 18 & 6 \\
$\quad$ Decerebrate & 15 & 17 \\
Purposive & & \\
Confused & 3 & 7 \\
Age group then* & 3 & 25 \\
2 & 27 & 9 \\
3 & 6 & 15 \\
Age group now* & & 19 \\
1 & 20 & 7 \\
2 & 4 & \\
3 & &
\end{tabular}

* See Method for definition.
TABLE 2

MEAN AGE OF PATIENTS (IN YEARS) AT EXAMINATION

\begin{tabular}{|c|c|c|c|c|}
\hline \multirow{3}{*}{$\begin{array}{l}\text { Locus of } \\
\text { impact }\end{array}$} & \multicolumn{4}{|c|}{ Impact group } \\
\hline & \multicolumn{2}{|c|}{ Left } & \multicolumn{2}{|c|}{ Right } \\
\hline & $\bar{X}$ & $S D$ & $\bar{X}$ & $S D$ \\
\hline $\begin{array}{l}\text { Frontal } \\
\text { Lateral } \\
\text { Parietal }\end{array}$ & $\begin{array}{l}42 \cdot 66 \\
45 \cdot 40 \\
39 \cdot 55\end{array}$ & $\begin{array}{r}8 \cdot 85 \\
9 \cdot 20 \\
13 \cdot 29\end{array}$ & $\begin{array}{l}37 \cdot 62 \\
36 \cdot 57 \\
49 \cdot 10\end{array}$ & $\begin{array}{l}10 \cdot 25 \\
15 \cdot 65 \\
12 \cdot 32\end{array}$ \\
\hline
\end{tabular}

The ages of these patients at the time of their reexamination ranged from 18 to 65 years (Tables 1 and 2). These data and those on the state of neurological responsiveness recorded on admission to hospital after the accident and subsequent progress were abstracted from the case records.

Four principal variables were examined in relation to the tests.

1. Post-traumatic amnesia Post-traumatic amnesia

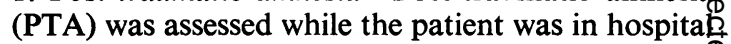
recovering from the accident and taken as the time that had elapsed between the head injury and the restoration of full orientation and normal registrao tion and recall of day-to-day events (as defined by Russell, 1932). Four durations of PTA were analysect -(1) 7 to 14 days, (2) 15 to 21 days, (3) 22 to 28 days? and (4) 29 days or longer. The range in this latter group was between five weeks and one year.

2. Initial neurological state The initial state of neurological responsiveness at the time of admission to hospital after the accident was classified as decerebrate, purposive, or confused. Patients in the decerebrate group were unresponsive to stimuli except by tonic extension of the legs with either tonic flexion or extension of the arms on one or both sides; those in the purposive group responded to painful stimuli other than by reflex posturing but did not obey commands; those classified as confused were disorientated but obeyed simple commands.

3. Age at time of accident The patients were divided into three groups according to their age at the time of the accident - (1) 5 to 15 years, (2) 16 to 35 years, and (3) 36 years and over.

4. Present age This referred to the age of the patients at the time of re-examination; they were grouped as (1) 16 to 35 years, (2) 36 to 55 years, and (3) 56 to 65 years. 
TABLE 3

MEAN RESULTS OF VERBAL TESTS

\begin{tabular}{|c|c|c|c|c|c|c|}
\hline & \multicolumn{4}{|c|}{ Impact group } & \multicolumn{2}{|c|}{$P$} \\
\hline & \multicolumn{2}{|c|}{ Left } & \multicolumn{2}{|c|}{ Right } & \multirow[t]{2}{*}{ Sig.* } & \multirow[t]{2}{*}{$I \dagger$} \\
\hline & $\bar{X}$ & $S D$ & $\bar{X}$ & $S D$ & & \\
\hline \multicolumn{7}{|c|}{$\begin{array}{l}\text { Object naming } \\
\text { latency and locus } \\
\text { of impact } \ddagger\end{array}$} \\
\hline $\mathbf{F}$ & $59 \cdot 10$ & $7 \cdot 26$ & $60 \cdot 42$ & $7 \cdot 34$ & & \\
\hline $\mathbf{L}$ & $58 \cdot 80$ & $7 \cdot 13$ & $62 \cdot 54$ & 8.90 & 0.05 & 0.05 \\
\hline $\mathbf{P}$ & 54.98 & $5 \cdot 29$ & $64 \cdot 86$ & $5 \cdot 59$ & & \\
\hline \multicolumn{7}{|c|}{$\begin{array}{l}\text { Object naming }(\%) \\
\text { and duration of } \\
\text { PTA }\end{array}$} \\
\hline 1 & $86 \cdot 53$ & $3 \cdot 32$ & $82 \cdot 40$ & $9 \cdot 60$ & & \\
\hline 2 & 88.95 & $10 \cdot 39$ & $77 \cdot 44$ & $12 \cdot 18$ & & \\
\hline 3 & $82 \cdot 45$ & 13.62 & $86 \cdot 80$ & $9 \cdot 38$ & 0.05 & 0.05 \\
\hline 4 & $90 \cdot 38$ & 1.92 & $72 \cdot 11$ & $14 \cdot 48$ & & \\
\hline \multicolumn{7}{|c|}{$\begin{array}{l}\text { Object naming }(\%) \\
\text { and neurological } \\
\text { status } \S\end{array}$} \\
\hline D & $89 \cdot 74$ & $1 \cdot 81$ & $75 \cdot 63$ & $13 \cdot 26$ & & \\
\hline $\mathbf{P}$ & $89 \cdot 17$ & $10 \cdot 68$ & $78 \cdot 84$ & 13.46 & 0.05 & \\
\hline C & $81 \cdot 58$ & $12 \cdot 21$ & $85 \cdot 10$ & $8 \cdot 53$ & & \\
\hline \multicolumn{7}{|c|}{$\begin{array}{l}\text { Object naming }(\%) \\
\text { and age group } \\
\text { at impact }\end{array}$} \\
\hline 1 & $96 \cdot 15$ & $3 \cdot 14$ & $76 \cdot 36$ & $3 \cdot 20$ & & \\
\hline 2 & $84 \cdot 97$ & $12 \cdot 28$ & $83 \cdot 71$ & $14 \cdot 32$ & 0.01 & \\
\hline 3 & 85.89 & $7 \cdot 90$ & 76.91 & $6 \cdot 77$ & & \\
\hline \multicolumn{7}{|c|}{$\begin{array}{l}\text { Object naming }(\%) \\
\text { and age group } \\
\text { now }\end{array}$} \\
\hline 1 & $88 \cdot 84$ & $14 \cdot 85$ & $81 \cdot 79$ & 10.64 & & \\
\hline 2 & $84 \cdot 29$ & $9 \cdot 38$ & 82.62 & $14 \cdot 20$ & 0.05 & \\
\hline 3 & 86.53 & $7 \cdot 92$ & $74 \cdot 71$ & $5 \cdot 74$ & & \\
\hline
\end{tabular}

* Level of significance for main effect of side of impact.

$\dagger$ Level of significance of interaction between side and site of impact. $\ddagger \mathrm{F}=$ Frontal. $\mathrm{L}=$ Lateral. $\mathrm{P}=$ Parietal.

$\$ \mathrm{D}=$ Decerebrate. $\mathrm{P}=$ Purposive. $\mathrm{C}=$ Confused.

\section{TESTS AND PROCEDURE}

Tests were chosen which previous work had shown to be sensitive to specific intellectual impairment resulting from focal lesions in the right or left cerebral hemisphere. They were divided into two broad categories, those which sampled verbal deficits and those which examined visuospatial impairment.

VERBAL TESTS Object Naming This test (Oldfield and Wingfield, 1965) has been shown to detect residual or slight nominal aphasia in patients with focal gunshot wounds (Newcombe, 1969). It consists in the independent presentation of 36 outline drawings (items 1-10 are practice items) of objects whose names fall at various word frequency ranges derived from the Thorndike-Lorge count (1944). Two measures were taken: the number of items correctly named (subsequently converted to percentages) and the time it took in milliseconds for each item to be
TABLE 3A

RESULTS OF VERBAL MEMORY AND LEARNING TESTS

\begin{tabular}{|c|c|c|c|c|c|}
\hline & \multicolumn{4}{|c|}{ Impact group } & \multirow[t]{3}{*}{$P^{*}$} \\
\hline & \multicolumn{2}{|c|}{ Left } & \multicolumn{2}{|c|}{ Right } & \\
\hline & $\bar{X}$ & $S D$ & $\bar{X}$ & $S D$ & \\
\hline \multicolumn{6}{|c|}{$\begin{array}{l}\text { Delayed story recall and } \\
\text { age group at impact }\end{array}$} \\
\hline 1 & $6 \cdot 83$ & $2 \cdot 01$ & $5 \cdot 71$ & 3.08 & \\
\hline 2 & $5 \cdot 81$ & $2 \cdot 85$ & $4 \cdot 64$ & $3 \cdot 17$ & 0.05 \\
\hline 3 & $7 \cdot 41$ & $3 \cdot 23$ & $3 \cdot 83$ & $1 \cdot 87$ & \\
\hline \multicolumn{6}{|c|}{$\begin{array}{l}\text { Digits forward and age } \\
\text { group at impact }\end{array}$} \\
\hline 1 & $7 \cdot 00$ & 0.81 & $5 \cdot 00$ & 0.92 & \\
\hline 2 & 6.40 & 1.06 & $6 \cdot 28$ & $1 \cdot 11$ & 0.01 \\
\hline 3 & $6 \cdot 50$ & 0.95 & $5 \cdot 66$ & $1 \cdot 24$ & \\
\hline \multicolumn{6}{|c|}{$\begin{array}{l}\text { Immediate story recall and } \\
\text { age group now }\end{array}$} \\
\hline 1 & $8 \cdot 00$ & $3 \cdot 62$ & 6.93 & $3 \cdot 59$ & \\
\hline 2 & 8.42 & $2 \cdot 58$ & $6 \cdot 68$ & $2 \cdot 90$ & 0.025 \\
\hline 3 & $8 \cdot 87$ & $2 \cdot 32$ & $5 \cdot 14$ & $1 \cdot 72$ & \\
\hline \multicolumn{6}{|c|}{$\begin{array}{l}\text { Digits forward and age } \\
\text { group now }\end{array}$} \\
\hline 1 & 6.58 & $1 \cdot 11$ & $5 \cdot 86$ & $1 \cdot 30$ & \\
\hline 2 & $6 \cdot 40$ & 0.96 & $6 \cdot 10$ & 1.07 & 0.05 \\
\hline 3 & $6 \cdot 50$ & $1 \cdot 11$ & $5 \cdot 57$ & $1 \cdot 29$ & \\
\hline \multicolumn{6}{|c|}{$\begin{array}{l}\text { Paired associates and locus } \\
\text { of impact }\end{array}$} \\
\hline $\mathrm{F}$ & $11 \cdot 38$ & 3.43 & $10 \cdot 25$ & $3 \cdot 79$ & \\
\hline $\mathrm{L}$ & $12 \cdot 78$ & $2 \cdot 17$ & $9 \cdot 85$ & $2 \cdot 98$ & 0.025 \\
\hline $\mathbf{P}$ & $12 \cdot 83$ & 3.04 & $10 \cdot 25$ & $4 \cdot 62$ & \\
\hline
\end{tabular}

* Level of significance for main effect of side of impact.

named (latency). Speed was emphasized and the inability to produce the name within four seconds was deemed a failure.

Wechsler Logical Sequences Two short stories from the Wechsler Memory Scale (1945) were read to the patient, who had to recall as much as possible after the presentation of each passage (immediate verbal recall). About one hour later, without warning, the patient again had to recall as much as possible of the story (delayed verbal recall). In both cases his score was the average number of items recalled.

Digits Forward A string of digits, beginning with three digits, was verbally presented by the examiner and the patient had to repeat them in the order in which they had been given. After each successful repetition a further digit was added until the patient had reached his asymptote.

Paired Associate Learning This test is a further subtest of the Wechsler Memory Scale. Ten pairs of words, some with easy associations-for example, up-down-and some with difficult associations-for example, cabbage-pen-were read to the patient. 
TABLE 3B

RESULTS OF VERBAL MEMORY AND LEARNING TESTS

\begin{tabular}{|c|c|c|c|c|c|}
\hline & \multicolumn{4}{|c|}{ Impact group } & \multirow[t]{3}{*}{$P^{*}$} \\
\hline & \multicolumn{2}{|c|}{ Left } & \multicolumn{2}{|c|}{ Right } & \\
\hline & $\bar{X}$ & $S D$ & $\bar{X}$ & $S D$ & \\
\hline \multicolumn{6}{|c|}{$\begin{array}{l}\text { Immediate story recall and } \\
\text { locus of impact }\end{array}$} \\
\hline $\mathbf{F}$ & 7.59 & 3.27 & $6 \cdot 58$ & 2.78 & \\
\hline L & $9 \cdot 14$ & 1.84 & $7 \cdot 14$ & 3.54 & 0.01 \\
\hline$\overline{\mathbf{P}}$ & $9 \cdot 27$ & $2 \cdot 19$ & 5.90 & $3 \cdot 32$ & \\
\hline \multicolumn{6}{|c|}{ Delayed story recall and } \\
\hline$\underset{F}{\text { locus }}$ & $5 \cdot 38$ & $3 \cdot 14$ & $4 \cdot 33$ & $2 \cdot 39$ & \\
\hline $\mathbf{L}$ & 6.85 & $2 \cdot 29$ & 5.71 & $3 \cdot 26$ & 0.05 \\
\hline $\mathbf{P}$ & $7 \cdot 22$ & $2 \cdot 17$ & $4 \cdot 65$ & 3.75 & \\
\hline \multicolumn{6}{|c|}{$\begin{array}{l}\text { Delayed story recall and } \\
\text { duration of PTA }\end{array}$} \\
\hline 1 & $7 \cdot 37$ & 3.47 & $6 \cdot 35$ & $2 \cdot 04$ & \\
\hline 2 & 6.40 & $2 \cdot 68$ & 3.93 & $2 \cdot 38$ & 0.05 \\
\hline 3 & 5.63 & 2.93 & $5 \cdot 25$ & 3.57 & 0.05 \\
\hline 4 & 6.00 & $2 \cdot 50$ & $2 \cdot 37$ & 1.55 & \\
\hline \multicolumn{6}{|c|}{$\begin{array}{l}\text { Immediate story recall and } \\
\text { neurological status }\end{array}$} \\
\hline D & $8 \cdot 83$ & $2 \cdot 01$ & 6.41 & 2.00 & \\
\hline $\mathbf{P}$ & $8 \cdot 50$ & $3 \cdot 15$ & 6.66 & 3.98 & 0.05 \\
\hline C & 8.03 & 2.84 & $6 \cdot 38$ & $2 \cdot 16$ & \\
\hline \multicolumn{6}{|c|}{$\begin{array}{l}\text { Delayed story recall and } \\
\text { neurological status }\end{array}$} \\
\hline D & $7 \cdot 83$ & 0.94 & $2 \cdot 41$ & $1 \cdot 30$ & \\
\hline $\bar{P}$ & $6 \cdot 11$ & 3.03 & $5 \cdot 38$ & 3.45 & 0.01 \\
\hline C & 5.90 & $2 \cdot 95$ & $4 \cdot 64$ & $2 \cdot 41$ & \\
\hline \multicolumn{6}{|c|}{$\begin{array}{l}\text { Immediate story recall and } \\
\text { age group at impact }\end{array}$} \\
\hline 1 & $9 \cdot 33$ & $1 \cdot 31$ & $7 \cdot 42$ & $3 \cdot 33$ & \\
\hline 2 & $7 \cdot 88$ & 3.05 & $6 \cdot 80$ & $3 \cdot 19$ & 0.01 \\
\hline 3 & $9 \cdot 83$ & $2 \cdot 44$ & $5 \cdot 00$ & 1.81 & \\
\hline
\end{tabular}

* Level of significance for main effect of side of impact.

The instructions and procedure followed those advised in the Wechsler Memory Manual. Immediate and delayed recall were measured.

VISUAL-SPATIAL TESTS Block Design This was taken from the Wechsler (1945) Adult Intelligence Scale and administered and scored in the usual manner.

Wechsler Designs Again this test was taken from the Wechsler Memory Scale and given according to the customary method. Immediate and delayed recall were measured.

Elithorn Lattice Maze This is essentially a paperand-pencil maze test; the patient had to trace a pathway through a series of black dots placed on the vertices of criss-crossing diagonal lines. In the righthand corner of each maze there was a number which informed the patient of the maximum number of dots he must incorporate for the successful comple-
TABLE 4

RESULTS OF NON-VERBAL TESTS

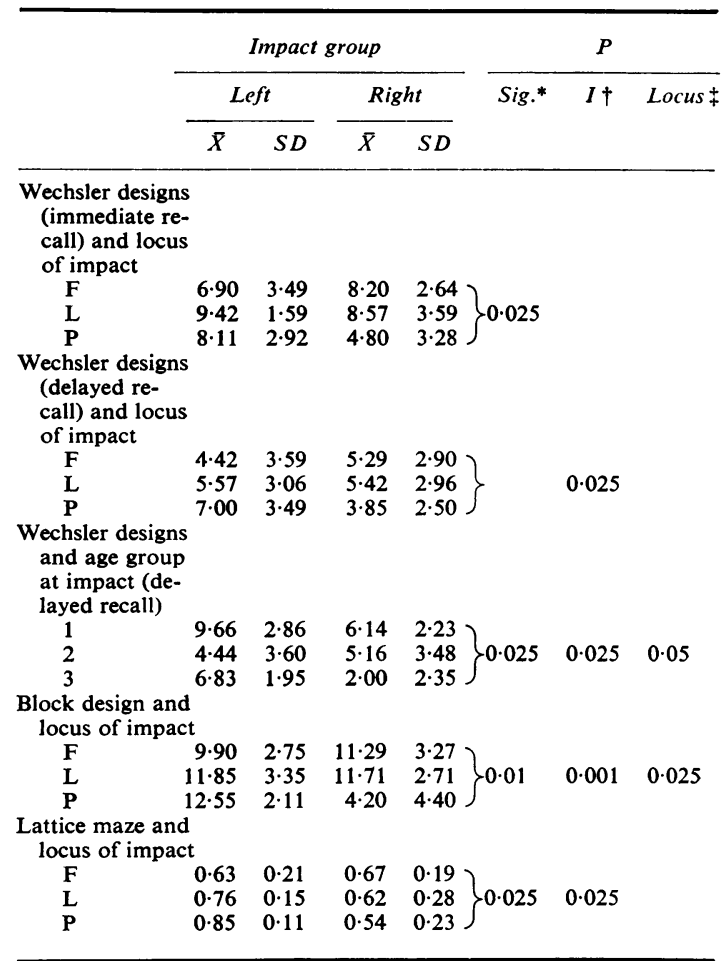

* Level of significance for main effect of side of impact.

+ Level of significance for interaction between side and locus of impact.

¥ Level of significance for main effect of locus.

tion of the maze (Elithorn et al., 1963). After three demonstrations the patient was allowed two minutes per maze; the test was stopped after three consecutive failures. The test was scored by dividing the number of mazes correct by the number attempted; a second score of number correct was also taken. A total testing time of 12 minutes was allowed.

The Progressive Matrices and Mill Hill Synonyms test were used for the assessment of IQ.

\section{RESULTS}

The results were analysed using Gumma (Baughan, 1973), a multivariate analysis of variance program, and run on the CDC 6600 computer. Only significant results are reported. Separate values were computed for main effects and interactions.

The right-impact group performed at a signifi- 
TABLE 4A

RESULTS OF NON-VERBAL TESTS

\begin{tabular}{|c|c|c|c|c|c|}
\hline & \multicolumn{4}{|c|}{ Impact group } & \multirow[t]{3}{*}{$P^{*}$} \\
\hline & \multicolumn{2}{|c|}{ Left } & \multicolumn{2}{|c|}{ Right } & \\
\hline & $\bar{X}$ & $S D$ & $\bar{X}$ & $S D$ & \\
\hline \multicolumn{6}{|c|}{$\begin{array}{l}\text { Lattice maze (raw scores) } \\
\text { and duration of PTA }\end{array}$} \\
\hline 1 & $11 \cdot 00$ & 1.42 & $8 \cdot 57$ & 3.00 & \\
\hline 2 & $9 \cdot 20$ & 3.72 & 6.00 & 3.02 & 0.025 \\
\hline 3 & $9 \cdot 20$ & 3.83 & $7 \cdot 57$ & 4.59 & 0.025 \\
\hline 4 & $9 \cdot 00$ & 1.00 & $5 \cdot 25$ & $2 \cdot 28$ & \\
\hline \multicolumn{6}{|c|}{$\begin{array}{l}\text { Lattice maze (raw scores) } \\
\text { and neurological status }\end{array}$} \\
\hline D & $9 \cdot 66$ & 1.24 & 7.00 & $3 \cdot 26$ & \\
\hline $\mathbf{P}$ & 9.66 & 2.78 & $6 \cdot 50$ & $4 \cdot 36$ & 0.025 \\
\hline C & 9.00 & $4 \cdot 48$ & $7 \cdot 29$ & $3 \cdot 15$ & \\
\hline \multicolumn{6}{|c|}{$\begin{array}{l}\text { Lattice maze (raw scores) } \\
\text { and age group at impact }\end{array}$} \\
\hline 1 & 11.66 & 0.47 & $9 \cdot 14$ & 2.74 & · \\
\hline 2 & 8.62 & 3.59 & 7.00 & 3.67 & 0.001 \\
\hline 3 & 11.66 & 2.56 & $4 \cdot 80$ & $3 \cdot 63$ & \\
\hline \multicolumn{6}{|c|}{$\begin{array}{l}\text { Lattice maze and age } \\
\text { group now }\end{array}$} \\
\hline 1 & 0.74 & $0 \cdot 16$ & 0.70 & $0 \cdot 17$ & \\
\hline 2 & 0.68 & 0.24 & 0.65 & $0 \cdot 19$ & 0.05 \\
\hline 3 & 0.76 & 0.04 & 0.44 & $0 \cdot 31$ & \\
\hline \multicolumn{6}{|c|}{$\begin{array}{l}\text { Lattice maze (raw scores) } \\
\text { and age group now }\end{array}$} \\
\hline 1 & $9 \cdot 41$ & $3 \cdot 12$ & & & \\
\hline 2 & $9 \cdot 15$ & 4.01 & $6 \cdot 84$ & 4.09 & 0.01 \\
\hline 3 & 10.50 & $1 \cdot 11$ & $4 \cdot 29$ & $3 \cdot 28$ & \\
\hline
\end{tabular}

* Level of significance for main effect of side of impact.

TABLE 5

IQ RESULTS

\begin{tabular}{|c|c|c|c|c|}
\hline & \multicolumn{4}{|c|}{ Impact group } \\
\hline & \multicolumn{2}{|c|}{ Left } & \multicolumn{2}{|c|}{ Right } \\
\hline & $\bar{X}$ & $S D$ & $\bar{X}$ & $S D$ \\
\hline \multicolumn{5}{|c|}{$\begin{array}{l}\text { Progressive matrices: percentile, } \\
\text { ranking, converted to IQ }\end{array}$} \\
\hline $\mathrm{F}$ & $91 \cdot 19$ & $23 \cdot 70$ & 93.62 & $25 \cdot 56$ \\
\hline L & $107 \cdot 57$ & $16 \cdot 70$ & $99 \cdot 28$ & $20 \cdot 27$ \\
\hline $\mathbf{P}$ & $99 \cdot 88$ & $11 \cdot 38$ & $80 \cdot 30$ & $41 \cdot 71$ \\
\hline \multicolumn{5}{|c|}{ Mill Hill vocabulary } \\
\hline $\mathrm{F}$ & 83.61 & $29 \cdot 54$ & $83 \cdot 54$ & $27 \cdot 86$ \\
\hline $\mathrm{L}$ & 91.00 & $39 \cdot 12$ & $90 \cdot 28$ & $12 \cdot 18$ \\
\hline $\mathbf{P}$ & $95 \cdot 11$ & $12 \cdot 44$ & 87.90 & 9.61 \\
\hline
\end{tabular}

cantly lower level of efficiency on all verbal tests than the left-impact group and also showed significantly more impairment on the visualspatial tasks. There were significant interactions between side and locus of impact, with the left frontal and right parietal impact groups having major deficits in visual-spatial skills (Tables 3,
$3 \mathrm{~A}, 3 \mathrm{~B}, 4$, and 4A). There were no significant differences in IQ (Table 5) between the left- and right-impact groups.

\section{DISCUSSION}

The results of this study show that there are differences between those patients whose impact was on the right and those whose impact was on the left. An impact on the right produces greater disruption of cognitive abilities. On verbal tasks the incidence of nominal aphasia and verbal memory deficits was higher with a right-sided impact, and these patients were also more impaired on visual-spatial tasks. These deficits are demonstrable 10 to 20 years after impact and do not seem to be associated with duration of PTA, initial neurological state, or age at which the impact was sustained.

The observation that verbal deficits follow right-sided impacts can be interpreted as evidence of contrecoup lesions. Furthermore, the observation of maximal impairment in verbal skills is consistent with the neuropathological findings of Courville (1942) and Gurdjian et al. (1943), that the temporal lobes are commonly the site of the greatest damage wherever the point of impact, the lobe opposite being almost invariably the more severely contused of the two.This is not to assume that the macroscopic contusions in relatively 'silent' areas of the temporal lobes are the cause of cognitive deficits. These contusions may do no more than indicate the sites of maximum sheer strains predicted by Holbourn which were considered by Strich (1961) to explain the widespread but asymmetrically distributed white matter destruction she found in the brains of patients dying after severe, uncomplicated closed head injury.

It is important to discuss the specific deficit seen in the object-naming test by the right-impact group since it might be argued that this was secondary to perceptual dysfunctioning - that is, subjects in this group were taking longer to identify the picture and therefore longer to name it - and that their performance on this test was not reflecting a true verbal deficit. However, qualitative analysis of their responses showed that their errors were more akin to those made by dysphasic patients than those made on the basis of perceptual deficit. 
The fact that the right-impact group showed significant impairment in visual-spatial tasks can be interpreted in two ways. It is possible that the impact may have caused subjacent focal injury and that superficial cortical contusions may have been present beneath the fracture. This view would be consistent with the results showing that the greatest impairment in visual-spatial tasks was observed in patients with a right parietal impact. On the other hand, the deficits on the visual-spatial tests can be interpreted on the basis of the contrecoup effect, in that poor performance by the right-impact group could be secondary to a verbal impairment. In this respect it is important to note the observations of Zangwill (1960), who pointed out that certain visual-spatial deficits can be associated with language disorders, and also those of Vignolo (1968), who found that aphasic patients showed a marked deficit on the Hidden Figure Test, primarily a test of visual perceptual ability. Furthermore, Milner (1969) has suggested that many visual memory tests are susceptible to verbal labelling.

Another point worthy of comment is the observation that marked visual-spatial deficits were related to a left frontal impact. This may be interpreted as a contrecoup effect, in that cognitive impairment usually seen after right hemisphere lesions emerged here after a left frontal blow. Alternatively the deficit seen in the leftfrontal group may be a function of either faulty visual scanning mechanisms, which have been reported (Luria, 1971) to be associated with frontal lesion, or inflexibility of strategy (Tow, 1955; Milner, 1969), which is also shown by patients with frontal lesions. Both these factors could result in poor performance with visualspatial tasks.

The fact that the left-impact group as a whole did not show visual-spatial deficits is puzzling, since presumably the left and right impacts were of similar severity and contrecoup effects could have been expected. These results relate to the observation of Heilbrun (1956), who suggested that while verbal difficulties tend to emerge after lesions in the left hemisphere visual-spatial disorders may not be apparent even though a lesion is known to be present in the right hemisphere. This agrees with the view of Teuber (1969), who emphasized the necessity for complex tasks to elicit visual-spatial deficits which may not emerge on routine tests. It is possible, therefore, that, although the visual tests used in this study are known to be sensitive to cognitive impairment resulting from damage to the right hemisphere, they were not sufficiently subtle to elicit evidence of contrecoup lesions in the left-impact group because these deficits may have been less severe. Alternatively these results may be explained on the differential process of reorganization and restoration of function, which may be dissimilar in the left and right hemispheres. However, evidence for this interpretation is not yet available.

It is important to note that in this study there was no significant relation between duration of PTA, initial neurological state, or age at which the impact was sustained and subsequent cognitive impairment.

The literature on the duration of PTA, and its relevance to subsequent sequelae is equivocal. Norrman and Svahn (1961) reported positive correlations between duration of PTA and the degree of visual and verbal memory deficits, and this was also the observation of Russell and Smith (1961). On the other hand, Anderson (1942) found no such relation and argued that psychogenic factors determined the quality of survival, and Dencker (1958) suggested that duration of PTA was not predictive of subsequent cognitive impairment. In the data presented here, although PTA did not emerge as a significant variable in its own right, inspection of the means for the right-impact group showed that performance was more depressed with a PTA of 15 to 21 days and a PTA of 29 days or more.

The present analysis did not include examination of the duration of the decerebrate response to stimulation, nor the duration of the purposive level of responsiveness recorded at the time of admission to hospital. It may be that this has obscured much of prognostic significance. However, relative to the assessment of cognitive impairment and initial neurological state the findings in the literature are also inconclusive. Robertson and Pollard (1966), Hendrick (1959), and Richardson (1963) found that decerebrate rigidity was not necessarily associated with severe cognitive sequelae, and Norrman and Svahn (1961) reported that the initial neurological state correlated only with a three-choice, reaction-time task. The results of this study sug- 
gest that those patients with a right-sided impact who were also decerebrate performed less well on the whole with verbal material than patients in other groups.

Age at which an impact is sustained has been regarded as the single most important variable in estimating the prospect of recovery, and Richardson (1963) reported that the proportion of vegetative survivors was greater in the older age groups. Inspection of the data for the rightimpact groups show that as age increased performance declined, but age itself did not emerge as a significant variable.

I am indebted to Mr. J. C. Scott, Mr. J. B. Pennybacker, and Mr. Walpole Lewin, formerly of the Accident and Neurosurgical Services at the Radcliffe Infirmary, Oxford, for permission to examine these patients previously under their care; to $\mathrm{Mr}$. Walpole Lewin and his colleagues, whose detailed documentation of the original case histories made this study possible; to Dr. F. Newcombe for advice on test selection; to Dr. B. Baughan, who wrote the computer program and gave advice on the statistical analysis; and to Dr. R. T. C. Pratt, Dr. M. Wyke, and the late Professor R. C. Oldfield for their critical comments on the manuscript. This work is a preliminary report of some psychological aspects examined in a study of the long-term prognosis of severe head injury carried out by Dr. A. H. Roberts from the Department of Neurology at The London Hospital, E.1, supervised by Mr. Walpole Lewin, of the Department of Neurological Surgery and Neurology, Addenbrooke's Hospital, Cambridge, and financed by a grant from the Department of Health and Social Security.

\section{REFERENCES}

Anderson, C. (1942). Chronic head cases. Lancet, 2, 1-4.

Baughan, B. (1973). Program GUMMA. The Universal Multivariate Analyser. Institute of Education Computing Centre: London.

Courville, C. B. (1942). Coup, contre-coup mechanism of craniocerebral injuries. Some observations. Archives of Surgery, 45, 19-43.

Darley, F. L. (ed.) (1967). Brain Mechanisms Underlying Speech and Language. Grune and Stratton: New York.

Dencker, S. J. (1958). A follow-up study of 128 closed head injuries in twins using co-twins as controls. Acta Psychiatrica et Neurologica, 33, Suppl. 123.

Dencker, S. J., and Löfving, B. (1958). A psychometric study of identical twins discordant for closed head injury. Acta Psychiatrica et Neurologica, 33, Suppl. 122.

Elithorn, A., Kerr, M., and Jones, D. (1963). A binary perceptual maze. American Journal of Psychology, 76, 506508.

Fahy, T. J., Irving, M. H., and Millac, P. (1967). Severe head injuries. A six-year follow-up. Lancet, 2, 475-479.
Gurdjian, E. S., Webster, J. E., and Arnkoff, H. (1943). Acute cranio-cerebral trauma. Surgical and pathologic considerations based upon 151 consecutive autopsies. Surgery, 13, 333-353.

Gurdjian, E. S., and Webster, J. E. (1958). Head Injuries, Mechanisms, Diagnosis and Management. Little, Brown: Boston.

Heilbrun, A. B., Jr. (1956). Psychological test performance as a function of lateral localization of cerebral lesion. Journal of Comparative and Physiological Psychology, 49, 10-14.

Heilman, K. M., Safran, A., and Geschwind, N. (1971). Closed head trauma and aphasia. Journal of Neurology, Neurosurgery, and Psychiatry, 34, 265-269.

Hendrick, E. B. (1959). The use of hypothermia in severe head injuries in childhood. Archives of Surgery, 79, 362364.

Holbourn, A. H. S. (1943). Mechanics of head injuries. Lancet, 2, 438-441.

Kimura, D. (1963). Right temporal-lobe damage. Archives of Neurology, 8, 264-271.

Lewin, W. (1965). Observations on prolonged unconsciousness after head injury. In Biochemical Aspects of Neurological Disorders, 2nd series, pp. 182-198. Edited by J. N. Cumings and M. Kremer. Blackwell: Oxford.

Lewin, W. (1967). Severe head injuries. Proceedings of Royal Society of Medicine, 60, 1208-1211.

Lindenberg, R., and Freytag, E. (1960). The mechanism of cerebral contusions. A pathologic-anatomic study. Archives of Pathology, 69, 440-469.

London, P. S. (1967). Some observations on the course of events after severe injury of the head. Annals of the Royal College of Surgeons, 41, 460-479.

Luria, A. R. (1971). The origin and cerebral organization of man's conscious action. In Proceedings of the Nineteenth International Congress of Psychology, London, 1969, pp. 37-52. British Psychological Society: London.

Miller, H., and Stern, G. (1965). The long-term prognosis of severe head injury. Lancet, 1, 225-229.

Milner, B., and Teuber, H.-L. Alteration of perception and memory in man. In Analysis of Behavioral Change, pp. 268375. Edited by L. Weiskrantz. Harper and Row: New York.

Milner, B. (1969). Residual intellectual and memory deficits after head injury. In The Late Effects of Head Injury, pp. 84-97. Edited by A. E. Walker, W. F. Caveness, and M. Critchley. Thomas: Springfield, Ill.

Newcombe, F. (1969). Missile Wounds of the Brain. Oxford University Press: London.

Norrman, B., and Svahn, K. (1961). A follow-up study of severe brain injuries. Acta Psychiatrica Scandinavica, 37, 236-264.

Oldfield, R. C., and Wingfield, A. (1965). Response latencies in naming objects. Quarterly Journal of Experimental Psychology, 17, 273-281.

Richardson, F. (1963). Some effects of severe head injury. A follow-up study of children and adolescents after protracted coma. Developmental Medicine and Child Neurology, $5,471-482$.

Robertson, R. C. L., and Pollard, C., Jr. (1955). Decerebrate state in children and adolescents. Journal of Neurosurgery, 12, 13-17.

Ruesch, J. (1944). Intellectual impairment in head injuries. American Journal of Psychiatry, 100, 480-496.

Russell, W. R. (1932). Cerebral involvement in head injury. Brain, 55, 549-603.

Russell, W. R., and Smith, A. (1961). Post-traumatic amnesia in closed head injury. Archives of Neurology (Chic.), 5, 4-17.

Symonds, C. P., and Russell, W. R. (1943). Accidental head injuries. Prognosis in service patients. Lancet, 1, 7-10. 
Strich, S. J. (1961). Shearing of nerve fibres as a cause of brain damage due to head injury. Lancet, $2,443-448$.

Teuber, H.-L. (1969). Neglected aspects of the post-traumatic syndrome. In The Late Effects of Head Injury, pp. 13-34. Edited by A. E. Walker, W. F. Caveness, and M. Critchley. Thomas: Springfield, III.

Thorndike, E. L., and Lorge, I. (1944). The Teacher's Word Book of 30,000 Words. Teachers College: Columbia University, N.Y.
Tow, P. M. (1955). Personality Changes following Frontal Leucotomy. Oxford University Press: London.

Vignolo, L. A. (1968). Factors underlying impairment of visual figure-ground discrimination of sorting tasks in hemisphere-damaged patients. Journal of Learning Disabilities, 1, 230-241.

Wechsler, D. (1945). A standardized memory scale for clinical use. Journal of Psychology, 19, 87-95.

Zangwill, O. L. (1960). Cerebral Dominance and its Relation to Psychological Function. Oliver and Boyd: Edinhurgh. 